\title{
DETERMINAÇÃO DE NITRITO EM ÁGUAS UTILIZANDO EXTRATO DE FLORES
}

\author{
Luiz Antônio Ramos, Carla Cristina Schmitt Cavalheiro e Éder Tadeu Gomes Cavalheiro* \\ Instituto de Química de São Carlos, Universidade de São Paulo, CP 780, 13560-970 São Carlos - SP
}

Recebido em 7/4/05; aceito em 4/11/05; publicado na web em 31/3/06

\begin{abstract}
DETERMINATION OF NITRITE IN WATER USING A FLOWER EXTRACT. Aspects of visible spectrophotometry can be presented to students using simple experiments in which the color of the crude extract of Macroptilium lathyroides (L.) Urb. is bleached in the presence of nitrite ions in acidic medium. The dependence of the absorption intensity with time, the reaction completeness and the Beer law can be demonstrated. Quantitative results for mineral water samples "contaminated" with nitrite ions were obtained from a method based on the Griess reaction and a procedure based on the bleaching reaction between the crude extract and $\mathrm{NO}_{2}^{-}$ions. Both the Griess and the bleaching reactions were found to be time dependent. Recoveries of about 100 $104 \%$ were obtained with these procedures. The use of natural dyes attracted students' interest enhancing the teaching process. Experiments performed by the teaching staff suggested that the proposed methodology can be performed in a $4 \mathrm{~h}$ class, with relative errors ranging from 0.19 to $1.86 \%$ in relation to the Griess method.
\end{abstract}

Keywords: acid-base chemistry; instrumental methods; water/water chemistry.

\section{INTRODUÇÃO}

O uso de extratos brutos de flores no ensino de química foi relatado em diversas oportunidades ${ }^{1-8}$, uma vez que tal abordagem pode ajudar o estudante a estabelecer uma conexão entre a química e as substâncias encontradas no seu cotidiano. As antocianinas são flavonóides presentes em um grande número de tecidos vegetais incluindo flores e frutas, conferindo-lhes as cores vermelha e azul ${ }^{9,10}$. Quando extraídas do meio natural, usualmente apresentam moléculas de açúcar ligadas aos grupos hidroxila nas posições 3 e/ou 4'. Quando livres destas moléculas de açúcar são chamadas antocianidinas, cuja estrutura genérica é apresentada na Figura 1 com atribuição usual dos átomos de carbono $^{10}$. Dependendo dos substituintes, nas posições R e R', define-se uma antocianidina diferente.<smiles>[R]c1cc(-c2[o+]c3cc(O)cc(O)c3cc2O)cc([R])c1O</smiles>

Figura 1. Estrutura de uma antocianidina genérica, mostrando as posições dos átomos de carbono. Dependendo dos substituintes $R$ e $R$ ' são definidas, antocianidinas diferente

A primeira aplicação da mudança da cor dos extratos brutos de flores no ensino de química foi relatada por Geissman ${ }^{11}$ e foi relacionada com as mudanças de cor em função do pH. Estas mudanças de cor ao mudar o $\mathrm{pH}$ foram usadas para ilustrar os princípios básicos de equilíbrio químico ${ }^{12,13}$; suas aplicações como indicadores em titulações ácido-base ${ }^{14}$; nos fundamentos dos métodos óticos de análise ${ }^{15}$ e em cromatografia em camada delgada ${ }^{16}$, usando extratos brutos de flores e da casca de feijão preto. A determinação

*e-mail: cavalheiro@iqsc.usp.br de sulfito em amostras de vinho branco ${ }^{17}$, baseada na reação de descoramento da solução contendo o extrato bruto de flores, também foi proposta. $\mathrm{O}$ baixo custo e a facilidade de preparação destes extratos permitem seu uso em qualquer escola. Em adição, qualquer espécie vegetal contendo antocianinas pode ser usada.

Neste trabalho, propõe-se o uso do extrato bruto extraído das flores de Macroptilium lathyroides (L.) Urb. na demonstração de princípios de espectrofotometria na região do visível e sua aplicação na determinação de nitrito artificialmente adicionado em amostras de água minerais. Os principais objetivos didáticos são a demonstração dos princípios básicos do desenvolvimento de um novo método ótico de análise, o uso de materiais alternativos em análise química e a comparação do novo método com procedimentos clássicos. A sensibilidade e a dependência das reações químicas em relação ao tempo também podem ser exploradas. O conjunto de experimentos aqui descrito poderia ser usado em projeto didático inserido em um curso de análise instrumental e/ou partes dele poderiam ser usadas em uma única aula, para demonstração de conteúdos mais específicos.

Os corantes naturais foram extraídos das flores de Macroptilium lathyroides (L.) Urb., (Phaseolus lathyroids (L.), Phaseolus semierectus (L.) D.C., Phaseolus crotalaroides Mort.), que é uma leguminosa de clima tropical originária da América do Sul. Tratase de uma planta de ocorrência anual encontrada no sul dos Estados Unidos, (Wilde bushbean, Phasey bean), nas Américas Central e do Sul (Frijol de monte/Venezuela, Frijol de los arrozales/ Colombia, Feijão de pombinha ou Feijão do campo/Brasil), Austrália (Murray phasey bean) e no Havaí (Wild pea bean). Informações adicionais sobre esta espécie podem ser encontradas na literatura especializada e na internet ${ }^{18}$.

Uma fotografia da flor do Macroptilium lathyroides (L.) Urb. é apresentada na Figura 2.

Outras espécies contendo antocianinas podem ser usadas como fonte dos extratos naturais, por ex. a Rhododendron simsii, azálea, uma planta de origem asiática, cuja flor é conhecida em todo mundo. Entretanto, a espécie sugerida inicialmente apresenta maior sensibilidade na análise, devido à maior quantidade de corantes em suas pétalas. 


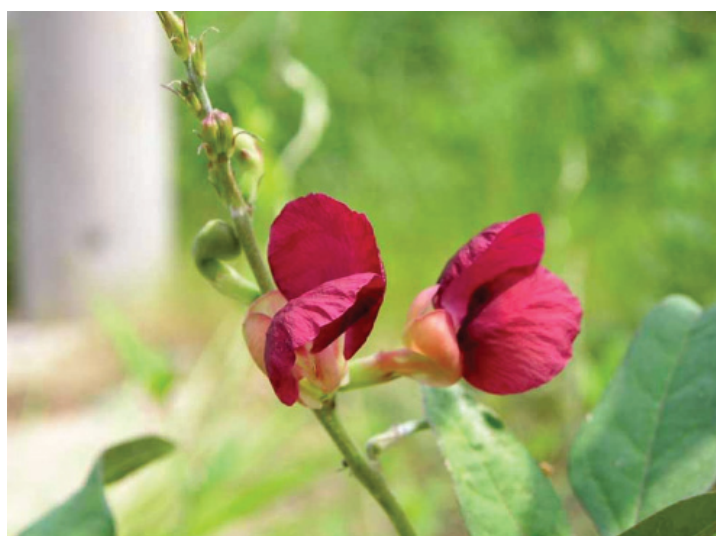

Figura 2. Flor de Macroptilium lathyroides (L.) Urb, popularmente conhecido como feijão do campo ou feijão de pombinha, encontrada no campus da UFSCar em São Carlos/SP

\section{FUNDAMENTAÇÃO}

\section{Considerações sobre a importância da determinação do nitrito}

A determinação de nitrito é um assunto importante, uma vez que ele é um aditivo alimentício muito usado na conservação de carnes e cura de embutidos. O nitrito também é um potencial agente poluidor de águas naturais, nas quais pode estar presente devido à decomposição de matéria orgânica nitrogenada.

O nitrito é a base conjugada do ácido nitroso, um ácido fraco $\operatorname{com} p K a=3,29^{19}$. A concentração de anions nitrito em águas naturais é raramente superior a $0,1 \mathrm{mg} \mathrm{L}^{-1}$. Entretanto, é adicionado à água usada em processos industriais, como inibidor da corrosão podendo, assim, estar presente em esgotos ${ }^{19}$. Por outro lado, sendo o nitrito um produto da redução do nitrato, estará freqüentemente presente em sistemas nos quais o íon nitrato atue como um oxidante. Neste sentido, o aumento da concentração do nitrato carregado pela lixiviação do solo de propriedades agrícolas para cursos d'águas, vem causando preocupação do ponto de vista ecológico. Neste caso, as principais fontes artificiais de nitrato são dejetos animais e nitrato de amônio não absorvido dos fertilizantes.

Embora o nitrito seja um poluente de águas, é muito útil quando usado como agente de cura, fixador de cor e conservante do "flavor" em diferentes produtos derivados de carne. O nitrito é também importante na proteção destes produtos contra microorganismos que podem causar o envenenamento, tal como Clostridium botulinum $^{20,21}$, que causa o botulismo. Neste caso, o nitrito é seguro se usado nos níveis recomendados, sendo importante o controle da sua concentração.

$\mathrm{O}$ excesso de nitrito em águas representa um potencial risco para a saúde, pois pode causar a meta-hemoglobinemia ("síndrome do bebê-azul") em recém-nascidos e mesmo em adultos com particular deficiência enzimática. A quantidade de nitrito deve também ser controlada devido à possível formação de nitrosaminas carcinogênicas, pela sua reação com aminas secundárias presentes no estômago de mamíferos ${ }^{22}$. O nitrato pode também ser convertido a nitrito pela ação de algumas enzimas da saliva e bactérias específicas, de acordo com a reação ${ }^{23}$ :

$\mathrm{NO}_{3}^{-}+2 \mathrm{H}^{+}+2 \mathrm{e}^{-} \rightarrow \mathrm{NO}_{2}^{-}+\mathrm{H}_{2} \mathrm{O}$

A síndrome do bebê-azul ocorre porque o nitrito oxida os íons ferrosos da hemoglobina a íons férricos gerando a meta-hemoglo- bina, que é menos eficiente na absorção e transferência de oxigênio para as células. De acordo com o grupo "KY Water Watch"24, o limite máximo de nitrito em águas ingeridas por bebês é de $1,0 \mathrm{mg} \mathrm{L}^{-1}$.

\section{A reação de Griess}

O método oficial para determinação do nitrito envolve, geralmente, os procedimentos espectrofotométricos baseados na reação de Griess ${ }^{25-27}$, na qual o nitrito reage com a sulfanilamida em meio ácido. $\mathrm{O}$ diazo composto formado reage com o cloridrato de $\mathrm{N}$-(1naftil)etilenodiamina (NED), gerando um composto de coloração vermelha intensa, de acordo a Equação 2. A reação é controlada pelo tempo, e o produto deve ser determinado entre 10 min e $2 \mathrm{~h}$ após a mistura dos reagentes.

A Equação 2 representa um mecanismo de reação usada no método de Griess, que foi proposto por Sawicki et al. após investigarem 52 sistemas diferentes ${ }^{25-27}$.

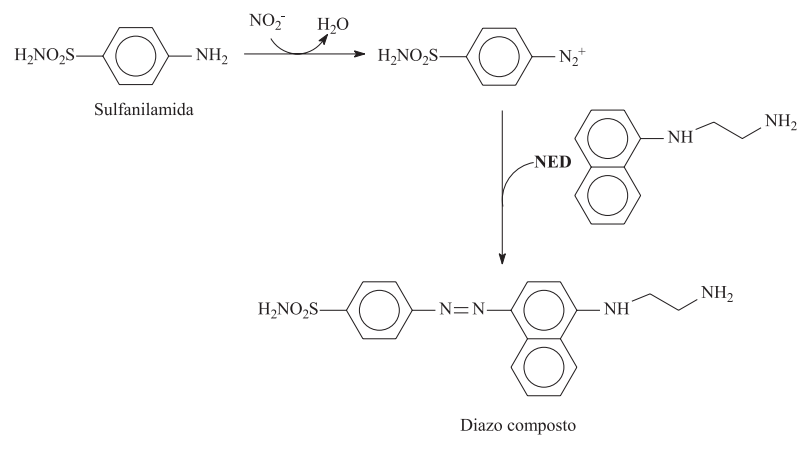

\section{PARTE EXPERIMENTAL}

\section{Instrumentação}

Todas as medidas podem ser realizadas em um espectrofotômetro convencional capaz de realizar leituras na região do visível. No caso deste trabalho, as medidas foram realizadas com auxílio de um espectrofotômetro Genesis 20 (Spectronic, EUA), usando cubetas de plástico (polimetacrilato) com caminho ótico de 1,0 cm.

\section{Preparação da solução padrão de nitrito $100 \mathrm{mg} \mathrm{L}^{-1}(100 \mathrm{ppm})$}

A solução padrão de íons nitrito $100 \mathrm{mg} \mathrm{L}^{-1}(100 \mathrm{ppm})$ foi preparada dissolvendo-se $0,1500 \mathrm{~g}$ de $\mathrm{NaNO}_{2}(0,1000 \mathrm{~g}$ do íon nitrito) em um balão volumétrico de 1,00 L, completando-se o volume com água destilada. $\mathrm{O}$ sal foi previamente seco em estufa à $105^{\circ} \mathrm{C}$ durante $1 \mathrm{~h}$ e resfriado em dessecador. Nesta etapa, recomenda-se rigor ao preparar esta solução, pois a mesma servirá de padrão e estoque para todas as diluições feitas durante todo o experimento. As soluções do nitrito devem ser preparadas recentemente (não mais que $6 \mathrm{~h}$ ) e o uso de um reagente PA recém-adquirido e de boa procedência é fortemente recomendado.

\section{As amostras de água "contaminadas"}

As amostras "contaminadas" podem ser preparadas adicionando-se nitrito de sódio em amostras de água mineral comercial. O cálculo e os resultados descritos aqui são para $5 \mathrm{ppm}$ do íon nitrito e permitem que os resultados permaneçam dentro dos limites analíticos da curva para o método proposto e de Griess. Isto pode ser obtido dissolvendo-se $5,00 \mathrm{~mL}$ de uma solução $100 \mathrm{ppm}$ de nitrito $\left(0,1500 \mathrm{~g}\right.$ de $\mathrm{NaNO}_{2}$ em 1,00 L) em 95,00 mL de água mineral. Se 
houver disponibilidade de tempo, três amostras de água de diferentes fontes podem ser preparadas permitindo executar cálculos estatísticos. A equipe instrutora pode executar esta etapa. Neste trabalho, a amostra de número 3 foi uma água mineral com gás, desgaseificada em banho de ultra-som por $20 \mathrm{~min}$.

\section{Preparação do extrato bruto de flores}

Dependendo da disponibilidade de tempo, os estudantes podem preparar os extratos brutos de flores antes do experimento ou, alternativamente, a equipe instrutora pode prepará-los e fornecer aos estudantes no início da aula. $\mathrm{O}$ extrato pode ser preparado com as pétalas recém-colhidas ou congeladas com cuidado. Para obtenção do extrato bruto foram utilizadas aproximadamente $25 \mathrm{~g}$ de pétalas de Macroptilium lathyroides (L.), ou outra espécie que contenha antocianinas, tais como o de Rodhodendron simsii - azálea, imersas em $100 \mathrm{~mL}$ de etanol. O tempo de extração estabelecido foi de $48 \mathrm{~h}$, mantendo-se o material em um frasco de vidro envolvido em papel alumínio e à temperatura ambiente ${ }^{12,17}$. Após filtração, o líquido resultante foi diluído para $250,0 \mathrm{~mL}$ com etanol anidro.

\section{Obtenção do espectro de absorção e determinação do comprimento de onda no máximo de absorção para os extratos brutos de flores}

Para obter os espectros de absorção sugere-se usar uma solução preparada transferindo-se $3,0 \mathrm{~mL}$ do extrato bruto para um balão volumétrico de $25,0 \mathrm{~mL}$ e completando-se o volume com uma solução de $\mathrm{HCl}$ 0,1 mol L-1. Recomenda-se medir o espectro 15 min após a preparação da solução, para determinar o comprimento de onda do máximo absorbância $\left(\lambda_{\max }\right)$, uma vez que a absorbância aumenta com o tempo, tendendo a um valor constante após $15 \mathrm{~min}$. Sugere-se obter o espectro ponto-a-ponto com intervalos de $10 \mathrm{~nm}$ entre $400-490 \mathrm{~nm}$, de $4 \mathrm{~nm}$ entre 490-550 nm, depois novamente intervalos de $10 \mathrm{~nm}$ entre $550-700 \mathrm{~nm}$. A partir do espectro (gráfico da absorbância em função do comprimento de onda), deve-se determinar o comprimento de onda do máximo de absorção. Alternativamente, pode-se medir a absorbância no $\lambda_{\max }$ para espectros de soluções contendo quantidades diferentes de extrato bruto e verificar a obediência à Lei da Lambert-Beer ${ }^{12}$.

\section{Determinação do nitrito usando o extrato bruto de flores}

Uma curva analítica pode ser obtida colocando-se 0,00 (branco), 200, 400, 600, 800 e $1000 \mu \mathrm{L}$ da solução padrão de nitrito 100 ppm e $1000 \mu \mathrm{L}$ do extrato bruto em 5 balões volumétricos diferentes de 25,0 mL e completando-se o volume com uma solução de $\mathrm{HCl} 0,1 \mathrm{~mol} \mathrm{~L}^{-1}$.

A absorbância no $\lambda_{\text {max }}$ (determinado como descrito acima) deve ser medida 10 min após preparar a solução. A reação de descoramento é dependente do tempo (como a reação de Griess). Assim, o tempo e as concentrações devem ser controlados com cuidado. Para obter uma curva analítica do nitrito entre 1,0-4,0 ppm, recomendase que a absorbância para a solução do branco em pH 1 após 10 min seja da ordem de 0,3 unidades. Os resultados obtidos devem ser lançados na Planilha 1.

\section{Análise da amostra usando o extrato bruto de flores}

A solução de trabalho pode ser preparada diluindo-se $10,0 \mathrm{~mL}$ da amostra de água "contaminada" e $1000 \mu \mathrm{L}$ do extrato bruto com $\mathrm{HCl}$ 0,10 $\mathrm{mol} \mathrm{L}^{-1}$ em um balão volumétrico de 25,0 mL. A concen- tração resultante do íon do nitrito na solução de trabalho fica em torno de 2,0 ppm. A absorbância no $\lambda_{\text {max }}$ é medida 10 min após preparar esta solução. Os resultados obtidos também devem ser lançados na Planilha 1.

Planilha 1. Resultados obtidos nas determinações de nitrito em amostras de água mineral "contaminadas", utilizando o método proposto com a reação de descoramento do extrato bruto de flores

\begin{tabular}{lllll}
\hline Soluções* & \multicolumn{4}{c}{ Absorbância em } \\
\cline { 2 - 5 } & \multicolumn{4}{c}{ Replicatas } \\
\cline { 2 - 5 } & $1^{\text {a }}$ & $2^{\text {a }}$ & $3^{\text {a }}$ & Média \pm SD \\
\hline
\end{tabular}

\begin{tabular}{ll}
\hline $\mathrm{NO}_{2}^{-}$ & $0,00 \mathrm{ppm}$ \\
$\mathrm{NO}_{2}^{-}$ & $0,80 \mathrm{ppm}$ \\
$\mathrm{NO}_{2}^{-}$ & $1,60 \mathrm{ppm}$ \\
$\mathrm{NO}_{2}^{-}$ & $2,40 \mathrm{ppm}$ \\
$\mathrm{NO}_{2}^{-}$ & $3,20 \mathrm{ppm}$ \\
$\mathrm{NO}_{2}^{-}$ & $4,00 \mathrm{ppm}$
\end{tabular}

Amostra 1

Amostra 2

Amostra 3

*Soluções obtidas respectivamente pela diluição de 0,00; 200; 400; 600; 800; $1000 \mu \mathrm{L}$ da solução padrão 100 ppm de nitrito

\section{Determinações analíticas com a reação de Griess}

Inicialmente uma solução de 3,5 ppm em íons nitrito deve ser preparada pela diluição de $35,00 \mathrm{~mL}$ da solução estoque padrão contendo 100 ppm do íon nitrito em 1,00 L. Outras duas soluções devem ser preparadas para a determinação, de acordo com o método de Griess. Solução A: deve ser recém-preparada, dissolvendose $0,5 \mathrm{~g}$ da sulfanilamida em uma mistura de $5,00 \mathrm{~mL}$ de $\mathrm{HCl}$ concentrado e 30,0 mL da água. A solução resultante deve ser diluída com água destilada, para 50,0 mL, em balão volumétrico. Solução B: deve ser recém-preparada, dissolvendo-se $0,05 \mathrm{~g}$ do cloridrato de $N$-(1-naftil)etilenodiamina (NED), em água e diluída para 50,0 $\mathrm{mL}$ em balão volumétrico. Esta solução tem que ser armazenada em um recipiente escuro. A curva analítica pode ser obtida diluindo-se 1,$00 ; 2,00 ; 3,00 ; 4,00$; e 5,00 mL da solução padrão 3,5 ppm do íon nitrito para $100,0 \mathrm{~mL}$ em cinco balões volumétricos diferentes, resultando nas seguintes concentrações 0,$80 ; 1,59 ; 2,39$; 3,19; 3,99 ppm ( $\left.\mathrm{mg} \mathrm{L}^{-1}\right)$. Então, 25,0 mL de cada padrão devem ser transferidos para béqueres (água para o branco) com $0,50 \mathrm{~mL}$ da solução A (sulfanilamida). Depois da mistura, a solução é deixada por 2-8 min a fim de completar a reação de diazotação (Equação 1). Finalmente, $0,50 \mathrm{~mL}$ da solução $\mathbf{B}$ (NED) são adicionadas à mistura resultante e homogeneizadas. A formação da cor é dependente do tempo e a absorbância em $543 \mathrm{~nm}$ foi medida após 15 min para o branco e os padrões. Os resultados obtidos devem ser lançados na Planilha 2.

\section{Análise das amostras usando o método de Griess}

A análise das amostras deve ser feita transferindo-se $600 \mu \mathrm{L}$ da água mineral "contaminada" para balões volumétricos de $25,0 \mathrm{~mL}$ e completando-se o volume com água destilada. Estas soluções são transferidas para béqueres e misturadas às soluções A e B exatamente como descrito acima, para os padrões. A formação da cor é dependente do tempo e a absorbância deve ser medida em 543 nm, após 15 min. Os resultados obtidos também devem ser lançados na Planilha 2. 
Planilha 2. Resultados obtidos nas determinações de nitrito em amostras de água mineral "contaminadas", utilizando o método de Griess

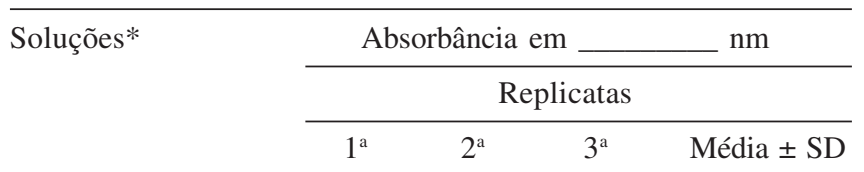

$\mathrm{NO}_{2}^{-} \quad 0,000 \mathrm{ppm}$

$\mathrm{NO}_{2}^{-} \quad 0,035 \mathrm{ppm}$

$\mathrm{NO}_{2}^{-} \quad 0,700 \mathrm{ppm}$

$\mathrm{NO}_{2}^{-} \quad 0,105 \mathrm{ppm}$

$\mathrm{NO}_{2}^{-} \quad 0,140 \mathrm{ppm}$

$\mathrm{NO}_{2}^{-} \quad 0,175 \mathrm{ppm}$

Amostra 1

Amostra 2

Amostra 3

*Soluções obtidas respectivamente pela diluição de 0,$00 ; 1,00 ; 2,00$;

3,$00 ; 4,00 ; 5,00 \mathrm{~mL}$ da solução padrão 3,5 ppm de nitrito.

\section{Resumos das atividades a serem desenvolvidas pelos alunos}

Deve ser solicitado aos estudantes que executem as seguintes atividades:

a. traçar o espectro de absorção para a solução do extrato bruto de flores e determinar o comprimento de onda no máximo de absorção;

b. traçar a curva analítica com o extrato bruto de flores e calcular o teor de nitrito nas amostras, usando os dados da Planilha 1. As medidas podem ser realizadas em triplicata;

c. traçar curva analítica com o método de Griess e calcular o teor de nitrito nas amostras, usando os dados da Planilha 2. As medidas podem ser realizadas em triplicata;

d. verificar se os resultados estão de acordo com regulamentos ambientais e com níveis definidos pela legislação local, caso haja tais recomendações;

e. se executar a experiência com replicatas, determinar o valor médio e o desvio padrão;

f. se for realizado o projeto completo, comparar os resultados do método de Griess e do extrato bruto de flores usando estatística de comparação de médias ${ }^{28}$;

g. comparar os resultados com os colegas de classe, que tenham desenvolvido o mesmo projeto.

\section{Cuidados com os reagentes utilizados}

A ingestão freqüente de pequenas doses de nitrito pode levar à hipotensão (diminuição na pressão sanguínea), taquicardia (aceleração do pulso), dor de cabeça e distúrbios visuais. A ingestão oral de grandes quantidades de nitrito pode causar náusea, vômito e, em casos extremos, coma. Os compostos carcinogênicos, como nitrosaminas, são sintetizados pela reação de nitritos com alguns produtos químicos presentes em alimentos, no estômago. O FDA, ("Food and Drug Administration" - órgão do governo norte-americano, que regula alimentos e produtos farmacêuticos), indica que a adição de vitamina $\mathrm{C}$ diminui a formação das nitrosaminas ${ }^{29}$. Apesar destes problemas, o nitrito pode ser usado como antídoto na ingestão de cianeto. Também atua como vasodilatador, diminuindo a pressão sanguínea e alivia espasmos musculares.

A sulfanilamida, além de ser um bactericida ${ }^{30}$, pode ser prejudicial se ingerida ou inalada, podendo agir como um irritante e provocar anemia ${ }^{31}$.
O cloridrato de $N$-(1-naftil)etilenodiamina (NED) é irritante aos olhos, ao sistema respiratório e à pele. Em caso de contato com olhos, deve-se enxaguar imediatamente com grande quantidade de água e procurar auxílio médico ${ }^{32}$.

\section{RESULTADOS ESPERADOS E DISCUSSÃO}

Os resultados descritos a seguir foram obtidos pelos autores deste trabalho. Inicialmente, pensou-se no uso de embutidos de carne como fonte de nitrito. Entretanto, o preparo de amostra requer um nível de treinamento e habilidade, que levaria a uma demora muito grande no desenvolvimento dos trabalhos.

Desta forma, uma prática semelhante, visando determinação de nitrito em águas, foi proposta a 20 alunos do curso de Engenharia de Produção Química da UFSCar. Os aspectos didáticos foram bastante satisfatórios quanto à motivação e ao interesse dos alunos pelos resultados obtidos, principalmente em relação ao uso de indicadores naturais, o que levou a uma facilitação da discussão do conteúdo envolvido: espectrofotometria, cinética de reação, determinação usando curva analítica, estatística de resultados, reação de Griess, reação de descoramento e química de antocianinas, comparação de resultados entre métodos analíticos, entre outros. $\mathrm{O}$ desenvolvimento dos trabalhos experimentais e sua discussão foram feitos em duas aulas de $4 \mathrm{~h}$ de duração.

Optou-se por usar as unidades em ppm $\left(\mathrm{mg} \mathrm{L}^{-1}\right)$, por serem muito usuais nas análises de água, inclusive nos rótulos das amostras empregadas.

\section{Espectros de absorção na região do visível}

Um espectro de absorção típico do extrato de Macroptilium lathyroides (L.) Urb. (feijão de pombinha) é apresentado na Figura 3 , com $\lambda_{\text {max }}$ em $526 \mathrm{~nm}$. A inserção nesta figura mostra em detalhe o comportamento da absorbância para diferentes quantidades: 1,0 -

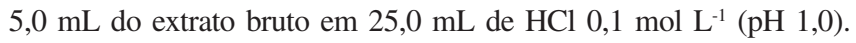
Um aumento linear da absorbância é observado, de acordo com a Lei de Lambert-Beer. Resultados similares foram observados para o extrato bruto da Rodhodendron simsii (azálea), com pequenas mudanças na posição do $\lambda_{\text {max }}$ (resultados não apresentados. Ver ref. 12).

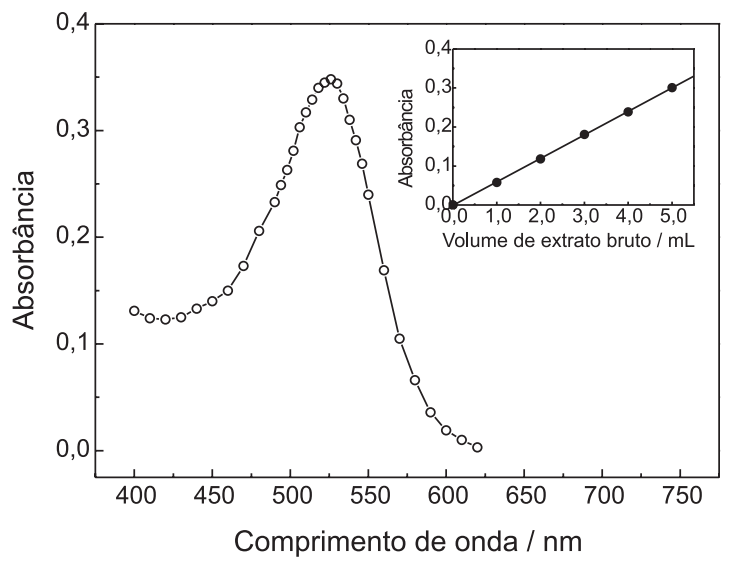

Figura 3. Espectro de absorção do extrato bruto das flores de Macroptilium lathyroides (L.) Urb. obtido após $20 \mathrm{~min}$ da diluição com $\mathrm{HCl}$ 0,10 mol de $\mathrm{L}^{-1}$. Em detalhe a demonstração do aumento na absorbância com a quantidade do extrato, que demonstra a obediência à Lei de Lambert-Beer em $526 \mathrm{~nm}$

Dependência da absorbância com o tempo, no $\lambda_{\max }$

A cor do extrato muda rapidamente de roxo para vermelho, 
<smiles></smiles><smiles>[CH]1[CH]C=C1</smiles>

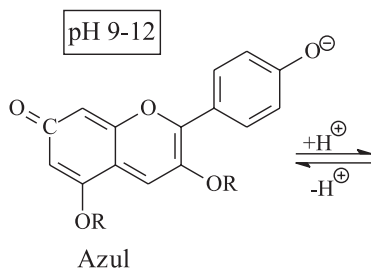
íon base anidro

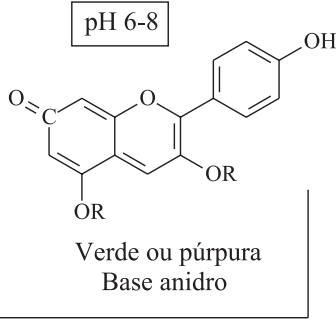

mudanças rápidas

$$
-\mathrm{H}_{+\mathrm{H}_{2} \mathrm{O}}^{\oplus} \stackrel{+\mathrm{H}^{\oplus}}{-\mathrm{H}_{2} \mathrm{O}}
$$

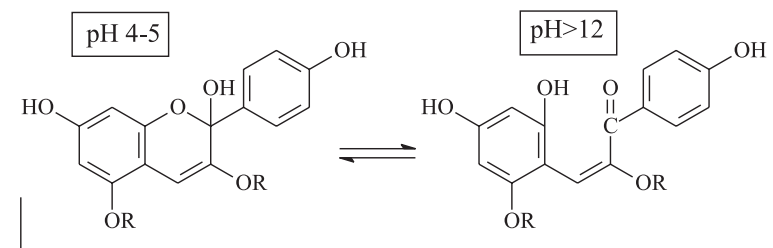

Incolor - Carbinol

Amarelo - Chalcona

Figura 4. Equilíbrios ácido-base envolvendo as antocianinas em diferentes $\mathrm{pH}$

com a adição de $\mathrm{HCl}$. Por outro lado, a intensidade da absorbância aumenta lentamente com o tempo. Brouillard et al. ${ }^{33,34}$ propuseram que um salto de $\mathrm{pH}$ de 5 para 1 causa uma reação rápida de protonação das antocianinas presentes no extrato. Tais equilíbrios ainda estão sob investigação e um conjunto de reações propostas para explicar tais mudanças da cor foi descrito por Epp ${ }^{35}$ e são apresentados na Figura 4.

A mudança na absorbância em $526 \mathrm{~nm}$ quando o extrato bruto é diluído com o $\mathrm{HCl} 0,1 \mathrm{~mol} \mathrm{~L}^{-1}$ é mostrada em Figura 5, que ilustra um comportamento assintótico, que tende a alcançar o equilíbrio após 15 min de reação. Na presença de íons nitrito o extrato colorido é descorado, entretanto a reação ainda não foi totalmente elucidada.

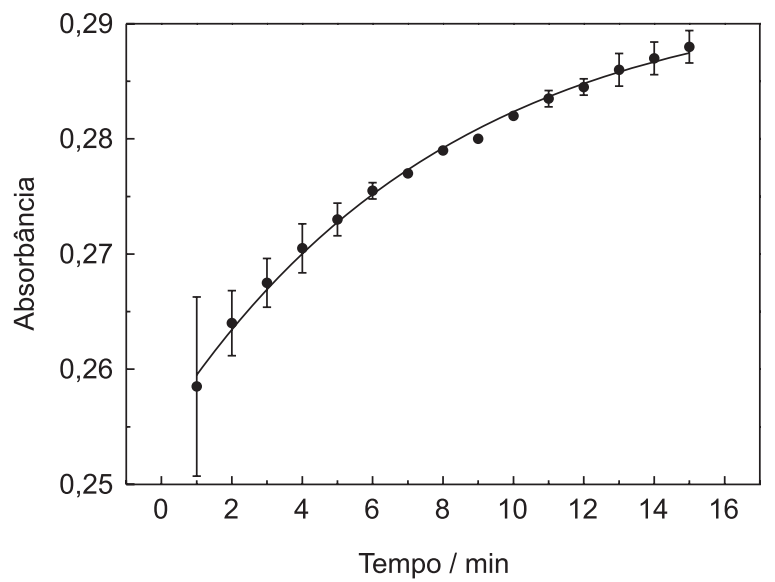

Figura 5. Mudanças na absorção do extrato bruto em uma solução contendo 1,0 $\mathrm{mL}$ do extrato bruto das flores de Macroptilium lathyroides (L.) Urb. e $10,0 \mathrm{~mL}$ de $\mathrm{HCl}$ 0,25 mol L-1 em um volume de 25,0 mL, (pH final 1.0) em função do tempo. $\lambda=526 \mathrm{~nm}$

No caso do sulfito, o ânion reage com a antocianina provocando seu descoramento ${ }^{17}$. A adição do $\mathrm{SO}_{3}{ }^{2-}$ na posição C-4 do íon flavílio bloqueia a delocalização eletrônica na molécula de antocianina, provocando diminuição na intensidade de cor da solução.
Apesar de Iacobucci e Sweeny ${ }^{36}$ terem descrito reações das antocianinas com diversos oxidantes, redutores, nucleófilos e eletrófilos, nenhuma referência foi encontrada sobre reações com nitrito e outros íons normalmente presentes em águas naturais, tais como o $\mathrm{Cl}^{-}, \mathrm{SO}_{4}^{2-}, \mathrm{NO}_{3}^{-}$, o $\mathrm{HCO}_{3}^{-}$e outros que poderiam interferir no procedimento proposto.

Fichtner et al..$^{37}$ descreveram que a reação de nucleófilos na posição C-4 ocorre mais rapidamente que na posição C-2 e investigaram a cinética das reações de íons flavílio com $\pi$-nucleófilos diferentes do nitrito. Com base em tais resultados, os autores concluíram que as substituições ocorrem principalmente na posição C-4. No presente estudo observou-se que o descoramento das antocianinas pelo nitrito é mais eficiente em $\mathrm{pH}$ 1,0.

A exemplo do que ocorre com o hipoclorito ${ }^{38}$, a reação poderia ser representada por:

antocianidina $+\mathrm{NO}_{2}^{-}+\mathrm{H}^{+} \rightarrow$ produto incolor desconhecido

Esta reação causará uma diminuição contínua na absorbância, enquanto compete com o equilíbrio ácido-base, como representado pelas curvas de absorbância em função do tempo, para diferentes concentrações de nitrito, apresentadas na Figura 6. Pode-se observar nesta figura que, para baixas concentrações de nitrito, somente após aproximadamente 5 min a reação de descoramento superará o aumento de absorbância, devido à formação da forma vermelha da antocianina. Este fato influencia marcadamente os parâmetros das curvas analíticas para o sistema extrato bruto nitrito, cuja reação também é dependente do tempo.

As melhores correlações lineares para curvas analíticas foram obtidas quando as absorbâncias foram lidas 5 ou 10 min após a mistura dos reagentes, como ilustrado na Figura 6. Quando o extrato de Rodhodendron simsii (azálea) foi usado, um comportamento similar foi observado. Para tempos de reação menores que 5 e maiores que 10 min, as curvas analíticas apresentam piores coeficientes de correlação linear, apesar de que as medidas tomadas após longos tempos de reação melhorem a sensibilidade, provocando maior descoramento da solução de corante natural.

Com base nestas observações, sugere-se o uso de 10 min uma vez que melhor sensibilidade pode ser obtida, com coeficiente de 


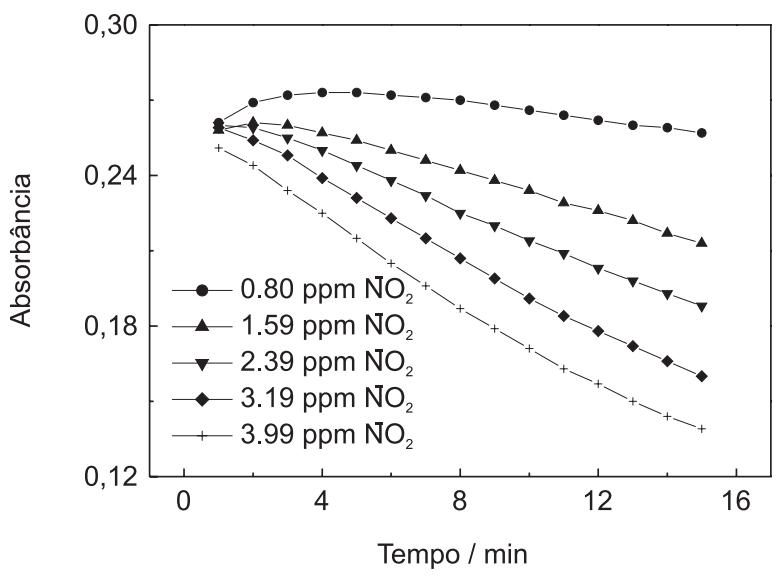

Figura 6. Dependência da absorbância com o tempo na reação de descoramento para diferentes concentrações de nitrito. Extrato bruto das

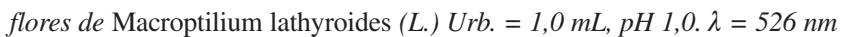

correlação indicando boa linearidade, pois a reação de descoramento se torna mais significativa que o equilíbrio ácido-base a partir de então.

As curvas analíticas obtidas após 1, 5, 10 e 15 min de reação, sob as mesmas circunstâncias são apresentadas na Figura 7, e representam a média de três determinações para cada um dos pa-

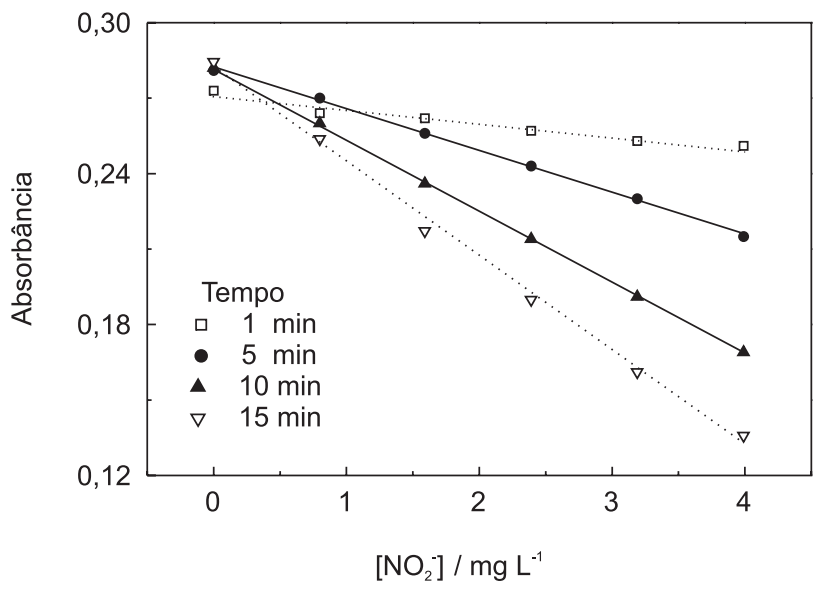

Figura 7. Curvas analíticas para nitrito determinadas em diferentes tempos após mistura dos reagentes. Extrato bruto de Macroptilium lathyroides $(L$.) Urb. $=1,0 \mathrm{~mL}, p H$ 1,0, $\lambda=526 \mathrm{~nm}$. Os dados da regressão linear são: $1 \mathrm{~min}$ : $A=0,273-0,0057\left[\mathrm{NO}_{2}^{-}\right](R=-0,8097, n=5) ; 5$ min: $A=0,281-0,0165$ $\left[\mathrm{NO}_{2}^{-}\right](R=-0,9992, n=5) ; 10 \mathrm{~min}: A=0,281-0,0283\left[\mathrm{NO}_{2}^{-}\right](R=-0,9999$, $n=5) ; 15$ min: $A=0,280-0,0369\left[\mathrm{NO}_{2}^{-}\right](R=-0,9945, n=5)$ drões. É importante observar que, devido à magnitude das concentrações de nitrito usadas neste trabalho, se sugere que a absorbância da solução do extrato bruto (branco) deva ser ao redor 0,3 unidades após 10 min e que a região linear de resposta para o íon do nitrito foi observada para concentrações acima de 1,0 ppm.

Uma curva analítica obtida sob as mesmas condições, mas usando o extrato bruto da Rodhodendron simsii (azálea), 10 min após misturar os reagentes obedeceu à relação linear: $\mathrm{Abs}=0,868-$ $0,00605\left[\mathrm{NO}_{2}^{-}\right](\mathrm{R}=-0,9992, \mathrm{n}=5)$, sugerindo que o extrato bruto de qualquer outra espécie contendo antocianinas pode ser usado neste tipo de determinação. Entretanto, a sensibilidade pode variar devido aos diferentes teores de corantes em cada espécie.

Os resultados para as amostras de água mineral "contaminadas" com 5,00 ppm de íons nitrito, determinados após $10 \mathrm{~min}$ de reação são apresentados na Tabela 1. Esta tabela compara também os resultados para o método proposto com os aqueles obtidos usando a reação de Griess, a qual também é dependente do tempo. Os resultados de ambos os métodos estão de acordo, com erros relativos menores que $2 \%$ em relação aos dois métodos e concordam entre si com $95 \%$ de confiança, de acordo com o teste $t$-Student para comparação de médias (Tabela 1$)^{28}$.

As medidas realizadas após 5 min de reação, permitiram aumentar a frequiência analítica, porém com ligeira perda de sensibilidade.

\section{DESTAQUES DIDÁTICOS}

a) O uso dos produtos químicos extraídos dos materiais do cotidiano, como as flores, realça a visão da importância da química na vida. Adicionalmente, a análise de nitrito por um método alternativo representa uma conexão desejável da química com a contaminação das águas e outros assuntos ambientais.

b) Antes de executar as análises do nitrito, foi solicitado aos estudantes que obtivessem o espectro de absorção dos extratos coloridos da flor, e determinassem o comprimento de onda no máximo de absorbância. Isto representa uma conexão desejável entre as cores e os espectros de absorção visualizados. A determinação ponto-a-ponto do espectro dará melhor compreensão do funcionamento do espectrofotômetro, em relação ao uso de instrumentos computadorizados, geralmente disponíveis nas etapas mais avançadas da carreira. Além disso, nem sempre se dispõe de espectrofotômetros sofisticados nos cursos de graduação.

c) A dependência do tempo da protonação, representada na Figura 5 , pode ser explorada em classe, conduzindo a uma discussão interessante da dependência dos métodos de análise em relação à cinética química, associada com o esquema da reação de Brouillard et al. ${ }^{33,34}$.

d) As diferentes curvas analíticas, mostradas na Figura 7, impli-

Tabela 1. Resultados da determinação do íon nitrito obtidos com a reação de descoramento do extrato bruto de flores e pela reação de Griess para as mesmas amostras de água mineral "contaminada”

\begin{tabular}{|c|c|c|c|c|c|}
\hline \multirow[b]{2}{*}{ Amostras } & \multicolumn{5}{|c|}{$\mathrm{NO}_{2}^{-} / \mathrm{mg} \mathrm{L}^{-1}$} \\
\hline & Método proposto & Griess & Recuperaçãof / \% & $|\% \mathrm{E}|^{\mathrm{b}}$ & $t_{\text {calc }}^{\mathrm{g}}$ \\
\hline $1^{\mathrm{d}}$ & $5,25 \pm 0,25^{\mathrm{c}}$ & $5,35 \pm 0,07$ & 100 & 1,86 & 0,667 \\
\hline $2^{\mathrm{d}}$ & $5,45 \pm 0,34$ & $5,39 \pm 0,03$ & 104 & 1,11 & 0,304 \\
\hline $3^{e}$ & $5,33 \pm 0,17$ & $5,34 \pm 0,05$ & 102 & 0,19 & 0,098 \\
\hline
\end{tabular}

${ }^{\mathrm{a}}$ Estes resultados foram obtidos para as amostras que continham $5,25 \mathrm{ppm}$ de nitrito; ${ }^{\mathrm{b}}|\% \mathrm{E}|=[($ Griess - proposto $) /$ Griess $] \mathrm{x} 100 ;{ }^{\mathrm{c}}$ média de três determinações \pm desvio padrão; ${ }^{d}$ água mineral sem gás; e água mineral desgaseificada em banho de ultra-som durante 20 min; ${ }^{\mathrm{f}}$ recuperação: [Proposto / 5,25] x 100; ${ }^{\mathrm{g}}$ valores calculados para o teste $t$-Student, para 95\% de confiança, $t=4,303(\mathrm{n}=3)^{28}$. 
cam que um menor tempo de análise é necessário, quando as determinações são executadas após 5 min. Por outro lado, a sensibilidade do método é melhor quando a análise é feita após 10 min de reação, pois a competição entre as reações químicas envolvidas é menor. Uma discussão interessante pode ser realizada sobre o compromisso entre um tempo mais curto de análise e uma maior sensibilidade.

e) O trabalho pode ser estendido e ampliado na sua abrangência abordando-se outros aspectos, tais como a cinética de reação de protonação, tratando-se os dados obtidos na Figura 4. O mecanismo envolvido nas mudanças estruturais também pode ser abordado. Tratando-se de uma química muito rica envolvida, muito se pode explorar do trabalho, a cargo e considerando os objetivos didáticos de sua aplicação.

\section{AGRADECIMENTOS}

Ao Prof. Dr. M.G. Neumann (IQSC-USP) pelos comentários e sugestões, à FAPESP pelo suporte financeiro (projetos 98/138730, 00/14486-2 e 04/00407-4) e ao Programa PROCONTES/USP.

\section{REFERÊNCIAS}

1. Alkema, J.; Seager, S. L.; J. Chem. Educ. 1982, 59, 183.

2. Geissman, T. A.; Crout, D. H. G.; Organic Chemistry of Secondary Plant Metabolism; Freeman, Cooper \& Cia: San Francisco, 1969, p. 182-209.

3. Forster, M.; J. Chem. Educ. 1978, 55, 107.

4. Séquin-Frey, M.; J. Chem. Educ. 1981, 58, 301.

5. Mebane, R. C.; Rybolt, T. R.; J. Chem. Educ. 1985, 62, 285.

6. Curtright, R. D.; Rynearson, J. A.; Markwell, J.; J. Chem. Educ. 1994, 71, 682.

7. Fossen, T.; Cabrita, L.; Andersen, O.; Food Chem. 1998, 63, 435.

8. Gibson, J. F.; Educ. Chem. 1997, 9, 123.

9. Larson, R. A.; Phytochemistry 1988, 27, 969.

10. Timberlake; C. F.; Bridle, P. Em The Flavonoids - Part I; Harborne, J.B.; Mabry, T. J.; Mabry, H., eds.; Academic Press: New York, 1975, p. 215224.

11. Geissman, T. A.; J. Chem. Educ. 1941, 18, 108.

12. Couto, A. B.; Ramos, L. A.; Cavalheiro, E. T. G.; Quim. Nova 1998, 21, 221.
13. Soares, M. H. F. B.; Boldrin-Silva, M. V.; Cavalheiro, E. T. G.; Eclet. Quim. 2001, 26, 225.

14. Soares, M. H. F. B.; Antunes, P. A.; Cavalheiro, E. T. G.; Quim. Nova 2001, 24, 408.

15. Soares, M. H. F. B.; Couto, A. B.; Ramos, L. A.; Cavalheiro, E. T. G.; Book of Abstracts, XI Euroanalysis, Lisbon, 2000.

16. Okumura, F.; Soares, M. H. F. B; Cavalheiro, E. T. G.; Quim. Nova 2002, 25,680 .

17. Soares, M. H. F. B.; Ramos, L. A.; Cavalheiro, E. T. G.; J. Chem. Educ. 2002, 79, 1111.

18. http://www.fao.org/ag/AGP/AGPC/doc/Gbase/DATA/Pf000050.htm, acessada em Março 2005.

19. Manahan, S. E.; Environmental Chemistry, $4^{\text {th }}$ ed., Brooks/Cole Publishing Co.: Monterey, 1984.

20. Swan, P. F.; Proc. Roy. Soc. Med. 1977, 70, 113.

21. Roberts, T. A.; Ingram, M. C. Em Proceedings of the second international symposium in nitrite on meat products; Tinbergen, B. J.; Kroll, B., eds.; Wageningen: PUDOC 1977, p. 29-38.

22. Patty, F. A.; Industrial Hygiene and Toxycology, Interscience: New York, 1963, vol. II, p. 917.

23. Baird, C.; Environmental Chemistry, $2^{\text {nd }}$ ed., W. H. Freeman \& Co.: New York, 1999.

24. http://www.state.ky.us/nrepc/water/wcpno.htm, acessada em Março 2005.

25. http://www.promega.com/tbs/tb229/tb229.pdf, acessada em Março 2005.

26. Revanasiddappa, K. K.; Bilwa, M.; Mikrochimica Acta 2001, 137, 249.

27. http://www.merck.de, acessada em Março 2005.

28. Harris, D. C.; Análise Química Quantitativa, 5ª ed., Riehl, C. A. S.; Guarino, A. W. S. trads., LTC: Rio de Janeiro, 2001, cap. 4, p. 66-71.

29. Lewis G. R.; 1001 Chemicals in everyday products, $2^{\text {nd }}$ ed., John Willey \& Sons: New York, 1999.

30. The Meck Index; Budavari, S., ed.; $12^{\text {th }}$ ed., Merck \& Co.: White House Station, 1996.

31. http://physchem.ox.ac.uk/MSDS/SU/sulfanilamide.html, acessada em Março 2005.

32. http://www.conncoll.edu/offices/envhealth/MSDS/botany/N/N-1-Naphthylethylenediamine-Dihydrochloride.html, acessada em Março 2005.

33. Brouillard, R.; Dubois, J. E.; J. Am. Chem. Soc. 1977, 99, 1359.

34. Brouillard, R.; Delaporte, B.; J. Am. Chem. Soc. 1977, 99, 8461.

35. Epp, D. N. Em The Chemistry of Food Dyes; Sarquis, M., ed.; Palette of Color Monograph Series, Terrific Science Press: Middletown, 1995, p. 11.

36. Iacobussi, G. A.; Sweeny, J. G.; Tetrahedron 1983, 39, 3005.

37. Fichtner, C.; Remennikov, G.; Mayr, H.; Eur. J. Org. Chem. 2001, 4451.

38. Ramos, L. A.; Prieto, K. R., Cavalheiro, C. C. S., Cavalheiro, E. T. G.; J. Chem. Educ 2005, 82, 1815 . 